
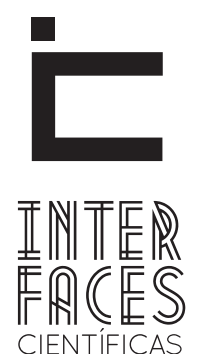

EDUCAÇÃO

ISSN IMPRESSO 2316-333X

E-ISSN 2316-3828

DOI-10.17564/2316-3828.2018v6n3p63-72

\title{
A PRODUÇÃO DE SABERES NUMA ERA DE TÉCNICA E CIBERCULTURA: DESAFIOS À PRÁTICA DOCENTE
}

\author{
THE PRODUCTION OF KNOWLEDGE IN AN ERA OF TECHNIQUE AND CIBERCULTURE: CHALLENGES TO TEACHER PRACTICE \\ LA PRODUCCIÓN DE SABERES EN UNA ERA DE TÉCNICA Y CIBERCULTURA: DESAFÍOS A LA PRÁCTICA DOCENTE
}

Ezir George Silva ${ }^{1}$

\section{RESUMO}

A proposta inscreve-se nos debates sobre Educação, Tecnologias da Informação e Prática Pedagógica. Seu objetivo é analisar, à luz das contribuições Filosóficas e Pedagógicas de Gabriel Marcel², o papel do educa-

2 Filósofo francês, nascido em Paris em 1889, onde foi diplomado em Filosofia aos vinte anos de idade e ensinou durante as duas grandes Guerras Mundiais. Desde criança se dedicou ao teatro onde buscou sempre fazer do drama uma expressão de sua reflexão filosófico-existencial. Após obter a agregação em Filosofia, Marcel passa a lecionar e exercer a atividade pedagógica em vários centros de Ensino Secundário. Como professor, ensinou em Vendôme (1911-1912), no Liceu Condorcet (1915-1918), em Sens (19191922), durante a segunda guerra, em substituição a professores mobilizados e/ou prisioneiros, no Liceu Louis-le-Grand, preparando os alunos da Escola Normal (1939-1940) e no l'Institut Montpellier (1941). Mais ainda: foi professor visitante na Universidade de Aberdeen, na Escócia, em 1951 e 1952, e na Universidade de Harvard, nos Estados Unidos, em 1961 e 1962. Em 1952, foi eleito membro da Académie des Sciences Politiques et Sociales de l'Institut dor numa era da técnica e cibercultura. Neste sentido, Marcel procura problematizar as diferenças entre as concepções técnica-funcional e humano-relacional, por compreender que elas representam as tendências que reconhecem o conceito de formabilidade como o princípio que caracteriza a educação numa determinada época, como ato de produzir ou deixar desenvolver do humano/educando, para atingir o fim que se encontra essencialmente nele ou que foi pretendido em suas possibilidades. Refletir sobre; quais as implicações que o modelo educativo da técnica, em torno

de France, além de atuar, de 1957 a 1961, como presidente da Association Montessori de France, tendo permanecido como presidente honorário até 0 fim de sua vida. Marcel morreu no dia 08 de abril de 1973 e deixou uma grande produção que foi fruto de sua busca itinerante pelo ser por meio do diálogo entre a crítica literária, a dramaturgia e a pesquisa filosófico-pedagógica. 
do qual se foi erigindo a educação contemporânea, infunde sobre as relações humanas e os desdobramentos das propostas e dos processos educacionais? 0 que o educador e a própria Pedagogia podem apreender dos estímulos dos cyberespaços? Do ponto de vista metodológico, optamos pela reflexão hermenêutico-ontológica, por compreendermos que ela está voltada para o tratamento interpretativo das informações e contribuições teóricas, à medida que visa desvelar as estruturas do desenvolvimento da existência do Ser e estabelecer uma íntima relação entre o su-

\section{ABSTRACT}

The proposal is part of the debates on Education, Information Technologies and Pedagogical Practice. Its objective is to analyze, in the light of the Philosophical and Pedagogical contributions of Gabriel Marcel, the role of the educator in an era of technique and cyberculture. In this sense, Marcel attempts to problematize the differences between technical-functional and human-relational conceptions, since they represent the tendencies that recognize the concept of formability as the principle that characterizes education at a given time, as an act of producing or letting develop Of the human / educating, to reach the end that is essentially in him or that was intended in his possibilities. Reflect on; What are the implications that the educational model of technology, around which contemporary education has been erected, infuses human relations and the unfolding of educational proposals and processes? What can teachers and pedagogy jeito pesquisador e sua pesquisa. Recorremos a estas inquietações, no âmbito de uma sociedade marcada pelo primado dos meios de comunicação de massa sobre o humano, do ter sobre o ser e da reprodução de saberes sobre o desvelamento do que é o homem e suas possibilidades.

\section{PALAVRAS-CHAVE}

Ensino. Cibercultura. Prática Docente. Gabriel Marcel. itself learn from the stimuli of the cyberspaces? From the methodological point of view, we chose hermeneutic-ontological reflection, because we understand that it is focused on the interpretative treatment of information and theoretical contributions, as it seeks to unveil the structures of the development of the existence of Being and establish an intimate relationship between the Subject researcher and his research. We have recourse to these concerns, within a society marked by the primacy of the mass media over the human, of having about being and of the reproduction of knowledge about the unveiling of what is man and his possibilities.

\section{KEYWORDS}

Teaching. Cyberculture. Teaching Practice. Gabriel Marcel. 


\section{RESUMEN}

La propuesta se inscribe en los debates sobre Educación, Tecnologías de la Información y Práctica pedagógica. Su objetivo es analizar, a la luz de las contribuciones filosóficas y pedagógicas de Gabriel Marcel, el papel del educador en una era de la técnica y la cibercultura. En este sentido, Marcel busca problematizar las diferencias entre las concepciones técnico-funcional y humano-relacional, por comprender que ellas representan las tendencias que reconocen el concepto de formabilidad como el principio que caracteriza la educación en una determinada época, como acto de producir o dejar desarrollar de lo humano/educando, para alcanzar el fin que se encuentra esencialmente en él o que fue pretendido en sus posibilidades. Reflexionar acerca las implicaciones que el modelo educativo de la técnica, en torno al cual se fue erigiendo la educación contemporánea, infunde sobre las relaciones humanas y los desdoblamientos de las propuestas y de los procesos educativos. ¿Lo que los profesores y la propia Pedagogía pueden

\section{INTRODUÇÃO}

O pensamento de Gabriel Marcel inscreve-se num contexto onde os discursos e debates sobre o predomínio da técnica, a emergência e a influência do cinema, do rádio, da televisão, da propaganda e das novas tecnologias da informação, como meios de comunicação de massa, estão a serviço da incidência da alienação e contra a dignidade do ser humano. Atrelados aos acontecimentos da Segunda Guerra Mundial, estes mecanismos de persuasão das consciências transformaram a existência humana num processo de produção e consumo, que resultou na obliteração do agir livre e da capacidade de o homem fazer-se autenticamente. Ao debruçar-se sobre o influxo destas técnicas de aviltamento sobre o comportamento do homem, o teórico empreende uma aguda crítica à realidade educativa do seu tempo, afirmando que "a aprehender de los estímulos de la cibercultura? Desde el punto de vista metodológico, optamos por la reflexión hermenéutico-ontológica, por comprender que la misma está orientada al tratamiento interpretativo de las informaciones y contribuciones teóricas, a medida que busca desvelar las estructuras del desarrollo de la existencia del Ser y establecer una íntima relación entre el sujeto investigador y su investigación. Hemos recurrido a estas inquietudes, en el marco de una sociedad marcada por el primado de los medios de comunicación de masa sobre lo humano, del tener sobre el ser y de la reproducción de saber sobre el desvelamiento de lo que es el hombre y sus posibilidades.

\section{PALABRAS- CLAVE}

Enseñanza. Cibercultura. Práctica Docente. Gabriel Marcel.

educação não é amparo onde há desmoronamentos lamentáveis" (MARCEL, 1951b, p. 40).

Essa foi uma época em que, segundo Marcel, a educação "[...] havia se transformado num sistema rígido e angustiante" (MARCEL, 1940, p. 126), pois, "[...] o ensino era penoso ao espírito discente, o sistema inteiro estava caindo aos pedaços, e era absolutamente certo, que para a maior parte das disciplinas o resultado fosse vazio e nulo" (MARCEL, 1951a, p. 45). Ao invés da educação desempenhar o papel de experiência formadora do desenvolvimento da consciência crítica dos alunos e núcleo fortalecedor de seu fulcro espiritual, transformou-se num tempo/espaço de conflitos e abstrações, que "[...] acabou contribuindo diretamente para debilitar a formação do ser humano ao seu estado anêmico" (MARCEL, 2005, p. 90). 
Diante destas dificuldades e sob a ameaça que o espírito de abstração tem exercido sobre as consciências humanas, num período de desenvolvimento tecnocientífico, Gabriel Marcel procura fazer, na obra Os homens contra o homem (1951b), uma reflexão-crítica sobre o papel do educador face à "essência da realidade espiritual [...] de um mundo destroçado e em guerra consigo mesmo" (MARCEL, 1951a, p. 14; 32). Levando em conta estes pressupostos, destacamos as exigências que pesam sobre o docente, numa era da técnica e cibercultura, procurando partir das condições gerais de suas possibilidades e desafios.

\section{DESAFIOS DO EDUCADOR NUMA ERA DE TÉCNICA E CIBERCULTURA}

O pensamento de Gabriel Marcel inscreve-se num contexto onde os discursos e debates sobre o predomínio da técnica, a emergência e a influência do cinema, do rádio, da televisão, da propaganda e das novas tecnologias da informação, como meios de comunicação de massa, estão a serviço da incidência da alienação e contra a dignidade do ser humano.

Atrelados aos acontecimentos da Segunda Guerra Mundial, estes mecanismos de persuasão das consciências transformaram a existência humana num processo de produção e consumo, que resultou na obliteração do agir livre e da capacidade de o homem fazer-se autenticamente. Ao debruçar-se sobre o influxo destas técnicas de aviltamento sobre o comportamento do homem, o teórico empreende uma aguda crítica à realidade educativa do seu tempo, afirmando que "a educação não é amparo onde há desmoronamentos lamentáveis" (MARCEL, 1951b, p. 40).

Esta foi uma época em que, segundo Marcel (1940, p. 126), a educação "[...] havia se transformado num sistema rígido e angustiante”, pois, “[...] o ensino era penoso ao espírito da criança, o sistema inteiro estava caindo aos pedaços, e era absolutamente certo, que para a maior parte das disciplinas o resultado fosse vazio e nulo" (MARCEL, 1951a, p. 45). Ao invés da educação desempenhar o papel de experiência formadora do desenvolvimento da consciência crítica dos alunos e núcleo fortalecedor de seu fulcro espiritual, transformou-se num tempo/espaço de conflitos e abstrações, que "[...] acabou contribuindo diretamente para debilitar a formação do ser ao seu estado anêmico" (MARCEL, 2005, p. 90).

Diante destas dificuldades e sob a ameaça que o espírito de abstração tem exercido sobre as consciências humanas, num período de desenvolvimento tecnocientífico, Gabriel Marcel procura fazer, na obra Os homens contra o homem (1951b), uma reflexão-crítica sobre o papel do educador face à "essência da realidade espiritual [...] de um mundo destroçado e em guerra consigo mesmo" (MARCEL, 1951a, p. 14; 32). Levando em conta estes pressupostos, destacamos as exigências que pesam sobre o docente, numa era da técnica e das tecnologias da informação, procurando partir das condições gerais de suas possibilidades.

Num sentido amplo, a ideia do educador sofreu, no âmbito da cultura da indústria e da técnica, uma verdadeira degradação, na medida em que a noção de sabedoria perdeu seu ethos e o conteúdo substancial daquilo que o identificava como um ser de espírito livre e conhecedor da realidade.

Como sujeito formador de opinião, e como alguém capaz de exercer influência sobre as outras pessoas, cabe ao docente procurar desenvolver, de modo consciente e contínuo, uma prática que esteja ancorada numa visão crítica dos princípios que a fundamentam, dos fins por ela visados e dos compromissos que dela são requeridos.

Diante das mudanças e de outras exigências e a partir dos aspectos complexos da educação, Gabriel Marcel compreende que, em primeiro lugar, o educador deve procurar 'manter-se em guarda contra sua pretensa capacidade', precisa “[...] reconhecer seus limites e necessidades e ver que há domínios onde a sua incompetência é absoluta" (MARCEL, 1951b, p. 97). A prática docente não acontece no âmbito de uma realidade resistente, bruta, imóvel e impossível de mutação. A era da técnica e da cibercultura é mutante, complexa e fluída.

Zygmunt Bauman, na obra Confiança e medo na cidade (2006), descreve o caráter dos desdobramen- 
tos destas mudanças como sendo próprios de uma época marcada pela migração populacional, por conflitos étnicos, religiosos e políticos, de agravamento das diferenças econômicas e sociais entre continentes, países e pessoas, degradação das condições materiais das populações, crescimento do desemprego, insegurança. Esta foi, ainda, uma época marcada pelo desenraizamento sócio-histórico, pela despersonalização das relações humanas, pelo fluxo intenso de produção e troca de informações, criação de cidades virtuais, alargamento da dimensão planetária e transgressão dos limites, que antes demarcavam os influxos da relação entre sujeito, espaço, tempo, distância, conhecimento, sentido, segurança e vida.

Em Aproximacion al misterio del ser: posición y aproximaciones concretas al misterio ontológico, Marcel (1987) anteviu os efeitos que a revolução industrial e o triunfalismo tecnológico trariam sobre a imagem que o homem constrói de si e de suas respectivas consequências, do modo como os cidadãos modernos haveriam de lidar com os novos aspectos deflagradores de sua realidade. Neste sentido, o teórico adverte que o educador não pode permitir que sua atuação incorra em frivolidades, falsas lisonjas e/ ou discursos pretensamente ideológicos e puramente publicitários.

Isto é, deve estar sempre em guarda contra uma pretensão incompatível com sua vocação verdadeira [...], porque o intelectual não se defronta com uma realidade resistente, como o operário ou o camponês, mas trabalha com palavras e o papel tudo consente. (MARCEL, 1951b, p. 98).

Se, por um lado, o educador pode achar, diante dos desafios que the cercam, que deve ficar no campo das afirmações abstratas e/ou dos saberes que se pretendem absolutos, por outra parte, ele precisa reconhecer que o engajamento da prática docente se expressa pelo modo como cada um se compromete com as questões concretas do Ser, por meio da relação entre os fazeres e os dizeres, que são realizados dentro e fora dos espaços possibilitadores das vivências educativas e das aprendizagens.
0 ato de ensinar exige que o docente faça o discernimento entre a arrogância acadêmica e o espontaneismo da prática, entre achar que sabe de tudo ou que não deve comprometer-se com nada; este ato implica em procurar reconhecer que há domínios e saberes que a sua especialidade não alcança. Implica, ainda, em buscar o conhecimento de outras competências e categorias humanas que consigam proporcionar, ao exercício do ofício docente, as condições necessárias para o desempenho desejável dos seus próprios saberes e realizações pedagógicas (MARCEL, 1955).

Neste sentido, ao educador cabe, num segundo momento, 'manter-se atento às questões humanas e às transformações do mundo', buscar questionar as ideologias e repelir os processos que reforçam a cultura do envilecimento e da submissão à servidão. 0 docente não pode colocar-se como "[...] um especialista de certo modo intoxicado pela própria especialidade" (MARCEL, 1951b, p. 92). A atuação docente nunca se dá no campo da neutralidade; jamais poderá fechar-se em si mesma, porque a produção dos saberes articula-se por meio das relações existentes entre a escola, a sociedade, o homem e a realidade.

A construção de conhecimentos se transforma, continuadamente, por meio do tempo e nos diversos espaços que vivemos e onde nos relacionamos. Posicionar-se indiferente aos processos de mudanças é subestimar a própria condição possível do Ser, é perder de vista a capacidade que o homem tem de criar, recriar e ressignificar os aspectos que constituem e dão sentido à sua própria visão de mundo.

Como Ser de presença, a relação do homem com o mundo é sempre livre, criativa, consciente e intencional. Movido pelo senso da presença, o agir do homem nunca é determinista, porque reconhece, na condição humana, a realidade da dimensão histórica. "A nossa própria situação histórica se transforma desde que nos pomos em guarda contra o que pode chamar-se a sedução do acontecimento" (MARCEL, 1951b, p. 211). Colocar-se em guarda representa procurar não repetir ou esquivar-se diante das práticas e posturas aviltantes que pretendem a humilhação do homem e sua degradação. "O silêncio em tal caso é cumplicidade [...]. 
Efetivamente - e sem sombra de hesitação - o primeiro dever do educador no mundo atual é combater o fanatismo sob qualquer forma que revista" (MARCEL, 1951b, p. 98-99).

Na determinação do pensamento, as palavras dos homens, em alguns momentos, constroem guetos, encerram-se em fórmulas precisas, comprometem a percepção da vida e tornam míope sua visão da existência. "Isolado o professor corre o risco de separar-se da vida e substituí-la insensivelmente pelo domínio de pensamento, espécie de jardim cerrado e bem tratado, onde ele muda cuidadosamente os arbustos" (MARCEL, 1951b, p. 93). Na servidão, as palavras docentes e discentes constroem submundos, fecham-se, caem em condicionamentos e tornam estes sujeitos, escravos de ideias e concepções que ameaçam a liberdade de si mesmos e a vitalidade da relação com os outros e o mundo. Onde quer que a educação seja assim entendida, as possibilidades de transformação humana e intervenção social são reduzidas.

$\mathrm{Na}$ relação entre conhecimento e mundo é que surge, num terceiro aspecto, a necessidade do educador 'procurar cultivar um olhar fenomenológico da situação fundamental do sujeito-educando' e empenhar-se em construir uma prática pedagógica do concreto. Para Marcel, as ideias e as concepções epistemológicas só fazem sentido quando são vistas a partir da própria realidade e do contexto imediato dos homens.

Realidade, existência e pensamento não devem ser concebidos separadamente. Na fratura desta relação estão presentes: a força dos processos de abstração, a energia dos pensamentos sectários, o imperialismo da ditadura da ignorância e a legitimação dos discursos, propostas e posturas absolutistas, intolerantes e excludentes de concepções, culturas, experiências e pessoas.

A construção de conhecimentos e habilidades constitui uma das dimensões da formação humana, algo que não deve ser confundido com a totalidade do processo formativo. A educação do homem não é uma experiência que nasce do abstrato para o concreto. Educação é um fenômeno que surge a partir do humano, à medida que encontra, nele e em sua existência, os aspectos fundantes de seu modo de ser, a razão primária e sentido último de seu existir. O sentido da educação encontra no homem seu real significado e valor. Â educação, pensada nestes termos, impõe-se a atenção à realidade do mundo e a atitude de respeito aos homens e às especificidades de suas vivências.

Em seu aspecto proposicional, a dimensão pedagógica da abordagem fenomenológica apresenta-se como um ato em que se reconhece a educação como uma experiência fundamental e profundamente humana. No sentido fenomenológico, o papel da educação é tentar compreender a realidade, buscar explicitar os aspectos do desenvolvimento da condição humana, por meio da apreensão do seu sentido e do desvelamento dos modos como a existência e as relações são experienciadas e apreendidas.

A desvinculação do educando da sua realidade é, para Marcel, um dos fatores que tem contribuído para o enfraquecimento das vozes individuais dos homens e o agravamento da profunda crise de identidade que as pessoas enfrentam, na era da técnica e das tecnologias da informação. Representa “[...] um dos dilemas que tem sido enfrentado por um grande número de educadores, [...] porque favorece a aparência de um relativismo sereno que, em nossa época, tende a mutilar tão perniciosamente o adequado juízo moral” (MARCEL, 2005, p. 86-87).

$\mathrm{Na}$ educação, o homem só se desenvolve humanamente quando ousa colocar, sob suspeita, as concepções e conclusões já assumidas; quando toma a iniciativa de problematizar suas verdades e a visão que tem de si e do mundo. Atrelado ao discurso existencial, a posição fenomenológica já anuncia que “a própria existência tem sentido e que toda significação é inseparável da existência” (REZENDE, 1990, p. 17).

A análise fenomenológica do saber nos coloca na perspectiva de que a educação consiste na tomada de consciência que o homem faz mediante a interpelação da existência. Os atos de ensinar e aprender não se limitam a um atuar mecânico de simples estímulo ou repetição de atividades. A educação, enquanto atitude fenomenológica, não deve desejar apenas desenvolver no aluno a capacidade de elaborar problemas 
e resolvê-los técnica e mecanicamente; senão, em ajudá-lo a descobrir “[...] como são dadas as respostas, mas, mais que isso, de que outras maneiras elas poderiam ou deveriam ser dadas" (REZENDE, 1990, p. 11). Na inquietação de si e do seu existir, o educando deve e/ou pode pretender a ampliação do olhar que perscruta a realidade da qual é sujeito criador.

Ao procurar cultivar um olhar fenomenológico da situação fundamental do sujeito-educando, não somente consideramos como importante a mudança na relação entre o homem e os espaços de produção do conhecimento. Faz-se necessário alterar a própria percepção que o eu passa a construir do tu. 0 olhar fenomenológico da realidade também pode contribuir para melhorar a qualidade da relação entre professores e alunos. Por meio dos saberes absolutos e das posturas herméticas da técnica, pode ser implantada uma radical ruptura entre um Ser e outro.

A partir das contribuições da atitude fenomenológica, professores e alunos poderão passar a considerar seus saberes como parte de uma realidade ampla, que, por meio do diálogo, tende a aprofundar-se e a alargar-se teórica e praticamente. Na busca pelo desdobramento dos significados, a obscuridade que separa os sujeitos é superada à medida que torna possível ver o outro como uma “[...] presença que está vinculada à alteridade" (MARCEL, 2003, p. 14); e também vinculada ao acolhimento, não só do que este outro diz, produz ou apresenta, como do que ele é e representa, enquanto Ser, subjetivamente encarnado.

Neste sentido, a educação pode tomar o mundo como referência, o educando, como centro e "as condições fenomenológicas como ato que implica sempre um comprometer-se" (MARCEL, 1951a, p. 347). Na intenção de corresponder às exigências deste comprometimento, cabe ao educador, num quarto momento, 'procurar desenvolver uma visão metafísica de suas concepções fundamentais'.

De acordo com Gabriel Marcel (1951b, p. 35), “a crise do homem ocidental é uma crise metafísica”, um acrisolar do humano, onde, na perda do contato real consigo, com o mundo e com os acontecimentos à sua volta, o homem se sente reduzido à simples menção abstrata. Na compreensão de Karl Jaspers, esta mudança de concepção sobre o humano acontece na era da técnica e das tecnologias da informação porque,

\begin{abstract}
[...] o conhecimento que se tem do homem passa a ser mais importante que o próprio homem, adota-se por vezes, atitude de singular superioridade, como a de quem possuísse conhecimento absoluto, capaz de tudo penetrar e tudo esclarecer. Dessas alturas, olha-se para as misérias humanas. Toma-se posição de Ser superior, que domina espiritualmente o mundo - o que se torna de um ridículo todo particular, quando se é pessoalmente um pigmeu. (JASPERS, 1965, p. 92).
\end{abstract}

Em nome do progresso e da produtividade, a que todo homem devia entregar-se, instaurou-se uma política da totalidade, a crença numa existência da uniformização e se propôs uma educação voltada para a aquisição de domínios científicos e especializações técnicas. Ademais, admite-se que as questões referentes à educação estão suficientemente construídas; assim, caberia uma preocupação com questões de ordem prática e de cunho metodológico: promover a implementação de propostas curriculares, cujos fundamentos apontam para uma concepção da realidade que se anuncia, pretensamente, como concretizada.

Entretanto, ao falar sobre a necessidade do educador procurar desenvolver uma visão metafísica de suas concepções fundamentais, Marcel propõe questionar a natureza do cerceamento do processo educativo, buscando problematizar as concepções de senso-comum, a partir de uma visão integral do ser humano e do reconhecimento de que "[...] há no ser humano tal como nós o conhecemos algo que se rebela contra esta espécie de violação ou desvinculação de que é vítima" (MARCEL, 1951a, p. 41).

Ao pretender construir uma concepção educativa do humano, a partir da visão metafísica de suas concepções fundamentais, Marcel anuncia total recusa a toda pretensão idealista do homem e da própria educação; e a procurar “[...] mostrar como o Idealismo tende inevitavelmente a eliminar toda consideração existencial” (MARCEL, 1968, p. 14). À educação, na intenção de superar toda concepção totalitária do ser humano, cabe, continuadamente, a renovação de 
seus pressupostos teóricos e a libertação de todas as categorias que limitam a compreensão humana à ordem da quantidade e do quantificável. "Cumpre à imaginação metafísica proceder a uma renovação das categorias fundamentais” (MARCEL, 1951b, p. 109) do Ser e sua formação.

Numa perspectiva metafísica, recomenda-se ao educador considerar outros olhares, a partir e sobre o humano, que consigam ajudar a suplantar toda tendência educativa maniqueísta, que pretenda determinar os modos de sua existência e os rumos de sua formação. Ao sucumbir à tentação do quantitativo sobre o metafísico, o educador renuncia àquilo que é próprio do humano.

Consciente de sua própria condição metafísica e movido por uma visão ampla acerca do humano, o educador tentará compreender que a educação não pode limitar-se a um simples processo de produção e rendimento e, que o educando não deverá ser pensado ou condicionado ao nível da máquina ou da função. O educador precisa conscientizar-se de que o indivíduo-educando não é redutível a uma ficha, nota, conceito, caderneta ou número, por meio de elementos determinantes de seu futuro ou da sorte que lhe caberá. Em tais condições, o Ser autenticamente criador é suplantado, ignorado, humilhado e aviltado na sua condição humana e na sua relação intersubjetiva.

Em Homo viator (2005), Gabriel Marcel afirma que a dimensão metafísica "constitui o núcleo de uma fenomenologia das relações entre eu e o próximo" (MARCEL, 1951a, p. 161). Este teórico enfatiza que o desvelar da existência humana passa, necessariamente, pelo caminho da comunhão intersubjetiva. Por meio da noção de comunhão intersubjetiva, professores e alunos poderão pensar e/ou superar a problemática dos sentimentos de isolamento, abandono e solidão que, numa era da técnica, da tecnologia e da criação dos cyberespaços, ao tempo em que contradizem a dimensão metafísica, também revelam que o homem é o único ser que não se desenvolve separado de outros da sua espécie.

A análise em torno da visão metafísica nos coloca na trilha do encontro com o outro, em direção à com- preensão de que a educação não se dá no encarceramento social, digital, conceptual ou institucional do aluno. A reflexão metafísica sobre o ser e sobre a educação sugere do entendimento de que a formação humana se faz na convivência fraterna, pela relação dialógica entre educadores, alunos e a comunidade em geral.

Os postulados da visão metafísica do humano e de sua relação intersubjetiva equivalem a dizer “[...] que o homem deve ser apreendido como uma participação efetiva" (MARCEL, 2003, p. 133), que caberá ao educador, num quinto momento, no comprometimento de si, "buscar a coerência entre um agir ético e uma visão ampla do humano', no âmbito de suas relações sociais e de seu fazer educativo. O fazer pedagógico nunca se encerra nele. Nenhuma teoria, método, conteúdo ou prática educativa terá sentido se não se relacionar ao homem e à sua própria existência. Pela educação, não somente educandos se formam, mas educadores também se fazem, se constituem, desenvolvem-se e podem avançar no processo de maturidade e formação humana.

Numa era da técnica e das tecnologias da informação, docentes e discentes são bombardeados, diariamente, por concepções, imagens, mensagens e informações que criam uma visão caricatural, que pretende subalternizar e desvalorar a própria condição humana. Essa leitura condicionada do Ser é fraticida da relação entre o agir e a visão que o educador pode vir a ter do aluno. Ao deixar de reconhecer o primado da dignidade humana sobre as fórmulas de pensamentos abstratos e reducionistas do homem, é possível que a relação pedagógica se mostre desinteressada ou pretensiosamente vazia. Ao invés de ser um processo de emancipação, a educação, nestes termos, poderá se converter num mecanismo de manipulação, um fio condutor do espírito à servidão e reprodutor da cultura da barbárie e da degradação social.

Ética, visão e relação intersubjetiva são aspectos do fazer educativo que se interpenetram, nutrem-se, ajudam-se e complementam-se. Articulados, poderão nos levar à compreensão de que "as ideias só têm vida se o espírito lhas conserva, julgando-as sempre, quer 
dizer, mantendo-se mais alto, e que elas deixam de ser boas e até de ser ideias quando deixam de ser a base sólida e a expressão em ato da liberdade interior" (MARCEL, 1951b, p. 100). Toda prática pedagógica que se pretende humana e humanizadora dos homens e dos processos educativos deve procurar buscar a coerência entre um agir ético e uma concepção ampla acerca do humano e dos processos possibilitadores do seu desenvolvimento.

A coerência entre os fazeres e os dizeres docentes só é possível a um Ser cuja existência esteja comprometida com sua própria formação. A articulação entre ser e fazer é mais importante ao educador, que seu discurso ou simples domínio cognitivo de teorias. $\mathrm{Na}$ ausência desta coerência, a prática docente "[...] tende invariavelmente a obliterar-se na consciência do educador para quem o seu sistema tende a substituir o mundo e a vida" (MARCEL, 1951b, p. 108).

"Assumir uma postura ética trata-se de uma opção decisiva, de uma escolha entre ser e não-ser" (MARCEL, 1951b, p. 113), entre enfeudar-se ou comprometer-se existencial e pedagogicamente. Implica em dizer que as intenções docentes e os fins da educação, por melhores que sejam, pouco servirão ao processo de formação humana dos alunos, se os próprios educadores não se tornarem uma expressão viva daquilo que ensinam e do seu comprometimento.

Neste sentido, não se deve entender que ao educador caberá indicar ao educando qual é o caminho a ser seguido ou, quem sabe, o exemplo a ser copiado. 0 que se pretende não é que o docente seja visto como um modelo ou padrão, senão, que cada aluno, contemplando seu agir ético, sinta-se motivado a realizar, na busca pela construção de si, “[...] não um trabalho malfeito, mas um trabalho coerente" (BUBER, 1969, p. 27).

Neste caso, o cuidado que se deve tomar é o de não converter um pensamento, que é específico e pessoal, numa leitura que se pretende totalitária dos homens e do mundo. Decerto, cumpre afirmar que um simples ponto de vista não pode determinar o nosso pensamento, encerrando-o em fórmulas precisas e que a construção do conhecimento sempre traz consigo o princípio de uma sublime irredutibilidade.
A produção do saber não pode se constituir num processo de sublimação do Ser, nem se transformar numa postura pela qual se impõem juízos de valor, de acordo com seus padrões últimos e individuais. "Considera que o professor, se quiser permanecer nos limites da honestidade intelectual, deve ter a consciência de que não é possível ter o domínio das rodas da história, fazendo-as girar de acordo com os seus desejos" (CARVALHO, 2005, p. 106). Ao educador, "categoricamente direi que ele não pode volver-se profeta" (MARCEL, 1951b, p. 114).

Aos educadores cabe instigar, no aluno, o senso crítico, a capacidade de não só entender os aspectos fundantes da realidade, como também, a motivação para questionar o porquê, o para quêe o modo de ser de cada um deles. Como Ser concreto, o homem precisa conservar sua integridade intelectual, a fim de dar sentido às suas utopias, responsabilidades e ações.

\section{CONSIDERAÇÕES FINAIS}

Ao educador, numa era de tecnologias da informação, cabe problematizar as concepções e aos saberes que orientam sua prática e denunciar, incansavelmente, a ilegitimidade das posturas aviltantes e ideológicas, que também estão presentes nos ciberespaços.

Sobre as questões e pistas alternativas que ficam abertas para outras produções, destacamos: as contribuições do estudo do pensamento marceliano, numa perspectiva hermenêutica e fenomenológica voltada para o uso das novas tecnologias da informação; estudo sobre a interface que há entre a cibercultura e a pedagogia dialógica do teatro marceliano; contribuições de Marcel para a construção de uma comunicação educativa; análise do uso da propaganda educativa nos ciberespaços e suas implicações para uma pedagogia da heteronomia.

E, acrescentamos, ainda, alternativas de pesquisa: o processo de educação para a cibercultura, a partir das contribuições teóricas de Gabriel Marcel, no contexto de uma sociedade democrática, marcada por posturas de intolerância e discriminação sócio-racial; 
implicações dos estudos da dramaturgia de Marcel para a formação do sujeito ético e de suas relações interpessoais nos espaços virtuais.

Enfim, o educador evita que os domínios da técnica e das tecnologias da informação violem e/ou determinem o fulcro de sua condição existencial, procurando sempre questioná-los, à luz da esperança e da fé que necessitamos sempre conservar com relação ao humano e suas possibilidades.

\section{REFERÊNCIAS}

BAUMAN, Zigmunt. Confiança e medo na cidade. Rio de Janeiro: Zahar, 2006.

\section{BUBER, Martin. Je et Tu, avant propos de Gabriel}

Marcel. Paris: Aubier, 1969.

\section{CARVALHO, Alonso Bezerra. Max Weber:}

modernidade, ciência e educação. Rio de Janeiro: Vozes, 2005.

\section{JASPERS, Karl. Introdução ao pensamento \\ filosófico. São Paulo: Cultrix,1965.}

MARCEL, Gabriel. Jornal metafísico. Madrid:

Gallimard, 1927.
MARCEL, Gabriel. De refus a linvocation. França: Librairie Gallimard, 1940.

MARCEL, Gabriel. El misterio del ser. Buenos Aires: Sudamericana, 1951a.

\section{MARCEL, Gabriel. Os homens contra o homem.}

Porto: Educação Nacional, 1951b.

MARCEL, Gabriel. Diário metafísico: 1928-1933.

Madrid: Ediciones Guadarrama, 1968.

\section{MARCEL, Gabriel. Aproximacion al misterio del}

ser: posición y aproximaciones concretas al mistério ontológico. Madrid: Ediciones Encuentro, 1987.

MARCEL, Gabriel. Ser y tener. 2.ed. Madrid: Caparrós Editores, 2003.

MARCEL, Gabriel. Homo viator: prolegómenos a una metafísica de la esperanza. Salamanca: Ediciones Sígueme, 2005.

\section{REZENDE, Antônio Muniz de. Concepção} fenomenológica da educação. São Paulo: Cortez; Autores Associados, 1990. 